EXTENDED REPORT

\title{
Severity and extent of osteoarthritis and low grade systemic inflammation as assessed by high sensitivity $C$ reactive protein
}

\author{
T Stürmer, H Brenner, W Koenig, K-P Günther
}

Ann Rheum Dis 2004;63:200-205. doi: 10.1136/ard.2003.007674

See end of article for authors' affiliations .....................

Correspondence to: Dr T Stürmer, Department of Epidemiology, German Centre for Research on Aging, Bergheimer Str 20, 69115 Heidelberg, Germany; til.sturmer@ post.harvard.edu

Accepted 29 June 2003
Background: Although osteoarthritis $(\mathrm{OA})$ is thought to derive from defective chondrocyte metabolism and thus inherently lack the large scale systemic response of rheumatoid arthritis, there is increasing interest in the acute phase proteins in OA.

Objective: To assess the association between high sensitivity $\mathrm{C}$ reactive protein (hsCRP) and severity and extent of OA in patients with advanced hip and knee OA.

Methods: Preoperative hsCRP was measured in frozen serum samples from 770 consecutive patients with hip or knee joint replacement due to advanced OA recruited between 1995 and 1996. Pain was measured by a visual analogue scale and the Western Ontario and McMaster Universities OA index (WOMAC). The extent of OA in different joints was assessed clinically and radiographically.

Results: The (geometric) mean hsCRP was $2.5 \mathrm{mg} / \mathrm{l}$ among all patients. Severity of pain was associated with mean hsCRP (adjusted elevation highest $v$ lowest quintile $=35 \%, p=0.01$ ) after controlling for known or suspected predictors of hsCRP, including age, smoking, and body mass index. Neither the bilateral nor the generalised extent of OA, nor any of the dimensions of the WOMAC were associated with mean hsCRP levels.

Conclusions: Severity of pain, but not extent of OA, was associated with hsCRP levels in this group of patients with advanced OA. Longitudinal studies with repeated assessments of hsCRP and pain are needed to assess the possible value of hsCRP for monitoring or predicting the clinical course of OA.
O steoarthritis (OA) is a common joint disease, especially in the elderly, ${ }^{1}$ and although OA inherently lacks the large scale systemic inflammatory response that is the hallmark of rheumatoid arthritis (RA), there are suggestions of a possible low grade systemic inflammatory response. $^{2-5}$

High sensitivity C reactive protein (hsCRP) is a sensitive marker of low grade systemic inflammation. Besides acute infections and known systemic inflammatory conditions, characteristics such as age, body mass index, diabetes, smoking, and alcohol consumption are known or suspected to influence hsCRP levels. ${ }^{67}$ These characteristics, therefore, need to be taken into account in the interpretation of hsCRP levels.

We performed a detailed systematic assessment of the association between various parameters of OA severity and extent, predictors of hsCRP, and levels of hsCRP in the Ulm Osteoarthritis Study.

\section{METHODS}

Between January 1995 and December 1996, 1037 consecutive patients under the age of 76 admitted to hospital for hip or knee joint replacement due to advanced radiographic OA were eligible for recruitment in four tertiary centres in southwest Germany. Patients with signs of RA (according to the American Rheumatism Association 1987 criteria $^{8}$ ), inflammatory joint disease (with history or laboratory evidence), hip fracture, or previous contralateral joint replacement were excluded. Of those eligible, 212 (20\%) were operated on before they could be examined and 16 (1.5\%) refused to participate. All remaining 809 participants gave written informed consent and were interviewed and examined by trained doctors according to a standardised questionnaire and examination procedure. The study was approved by the ethics review committee of the faculty of medicine of the university of Ulm and has been described in detail elsewhere. ${ }^{9}$

After documentation of high inter- and intrarater reliability, ${ }^{10}{ }^{11}$ hip and knee radiographs (both sides) were graded according to the Kellgren and Lawrence (K\&L) score using a standard reference atlas from 0 to $4 .^{12}{ }^{13}$ All participants had radiographic OA of the joint being replaced because this was an inclusion criterion. If radiographic OA $(K \& L \geqslant 2)$ was present in the joint contralateral to the one being replaced, the participant was categorised as having bilateral OA.

In addition, hand radiographs were taken and all finger joints (proximal interphalangeal and distal interphalangeal) and first carpometacarpal joints were studied for joint space narrowing, osteophytes, and subchondral sclerosis according to the atlas of Altman et al. ${ }^{14}$ If OA was found in two or more finger joints and one or both lst carpometacarpal joints in addition to the OA of the replaced joint, the participant had radiographically defined $\mathrm{OA}$ in at least three separate joint groups and was considered as having generalised OA. ${ }^{15}$

Current intensity of pain in the joint to be replaced and the contralateral joint was separately assessed using visual analogue scales (VAS) with a horizontal bar of $10 \mathrm{~cm}$ length with vertical bars at both ends marked "no pain" (left) and "extreme pain" (right). ${ }^{16}$ This question was not defined for any specific situation or time scale and was part of a module asking different questions about pain in the hip and knee joints, respectively, including duration of pain, pain with

\footnotetext{
Abbreviations: hsCRP, high sensitivity $C$ reactive protein; K\&L, Kellgren and Lawrence; NSAIDs, non-steroidal anti-inflammatory drugs; OA, osteoarthritis; RA, rheumatoid arthritis; VAS, visual analogue scale
} 
different activities, and diurnal variation. The VAS score was measured in millimetres from the left hand vertical bar to a vertical line through the midpoint of the corresponding marking (usually a cross). Pain, swelling, and stiffness in 23 different joint regions, including different parts of the spine (neck, thorax, and lower back), shoulders (both sides separately for all paired joints), elbows, hands (wrist, thumb base, metacarpophalangeal, proximal interphalangeal, and distal interphalangeal joints), as well as lower extremity (hip, knees, ankle, and lst metatarsophalangeal joint), with the exception of the affected joint (and the contralateral joint), were separately asked for. Painful joint regions were first summed and then dichotomised into one or more painful joint region (at least one painful joint region in addition to the joint being replaced) versus no additional painful joint region. Pain during different tasks, stiffness, and functional impairment were assessed using the hip- and knee-specific Western Ontario and McMaster Universities OA index $(\text { WOMAC })^{17}$ on a five point Likert scale ranging from 0 (none) to 4 (extreme). According to the number of items, the corresponding maximum (most extreme) values were 20, 8 , and 68 for pain, stiffness, and functional impairment, respectively.

The brand names of all drugs taken daily during the last three months before hospital admission were asked for during the interview. Drugs were classified according to the Anatomical-Therapeutical-Chemical classification (ATC classification, WHO Collaborating Centre for Drug Statistics Methodology, Oslo 1993) by a pharmacist. The coding allowed for up to three different active ingredients per drug and up to 15 different drugs per patient. Patients using systemic steroids $(n=6)$ were excluded from all analyses, because steroids are usually given for systemic inflammation and are known to affect serum CRP.

Body weight and height were obtained by interview during the physical examination. Body mass index was calculated as a measure of weight relative to the height by dividing the weight in kilograms $(\mathrm{kg})$ by the squared height in metres (m).

Non-fasting serum samples were obtained preoperatively by standard venepuncture, stored at $-80^{\circ} \mathrm{C}$, and analysed together in a central laboratory. High sensitivity CRP was measured by nephelometric method using a commercial kit (NA-latex CRP, Behring Werke, Marburg, Germany) calibrated with the WHO reference standard 85/506.

\section{Statistical analyses}

We first described the patients with respect to sociodemographic factors as well as markers of severity and extent of OA. Because serum hsCRP values were not normally distributed, log transformed (geometric) means were then calculated for various markers of severity and extent of OA. Finally, bivariate (table 2) and multivariable (table 3) linear regression models with the log transformed serum hsCRP values as dependent variable were used to assess the independent impact of severity and extent of OA and other factors on the geometric mean of serum hsCRP concentrations. Regression coefficients from the multivariable model were exponentiated to allow presentation of the associations of the independent variables as a percentage change in serum hsCRP values.

Radiographic extent of OA (bilateral or generalised), intensity of pain in the operated joint, additional painful joint regions, and the WOMAC subscales (pain, stiffness, function) were considered as predictor variables in patients with OA.

The following variables were considered as possible confounders in multivariable analyses: age (continuous), sex, body mass index (weight in kg divided by squared height in $\mathrm{m}$, continuous), history of coronary artery disease, history of congestive heart failure, serum cholesterol level, use of antihyperlipidaemic drugs, hypertension (systolic blood pressure $\geqslant 160 \mathrm{~mm} \mathrm{Hg}$ and/or diastolic blood pressure $\geqslant 95 \mathrm{~mm} \mathrm{Hg}$ and/or use of a antihypertensive drug), diabetes (history or use of oral antidiabetics or insulin), gout (history or use of uricosuric or uricostatic drug), smoking (current and former), alcohol consumption (three categories), self reported current or former heavy physical exertion at work or at home, and use of non-steroidal anti-inflammatory drugs (NSAIDs), diuretics, angiotensin converting enzyme inhibitors, and oestrogen replacement therapy, as well as an impaired renal function (defined as an estimated serum creatinine clearance below $60 \mathrm{ml} / \mathrm{min}^{18}$ ).

All covariates associated with serum hsCRP in the bivariate analyses were included in the final multivariable model.

\section{RESULTS}

Frozen serum samples were available for 771 patients, and hsCRP could be measured in 770 patients $(95.2 \%$ of all 809 patients). The mean age of these patients was 63 years, and $63 \%$ were women (table 1). More than half of the patients were hypertensive and 19\% reported a history of congestive heart failure. Regular current use of NSAIDs was very common, followed by use of diuretics by almost a quarter of the patients. More than $40 \%$ were current or former smokers. Most patients consumed $<10$ grams of pure alcohol a day.

About half of the patients had OA of the hip or the knee, each, and mean serum hsCRP levels were almost identical in these two patient groups (table 2). Most patients had bilateral OA, associated with slightly (not significantly) higher serum hsCRP levels and more than a quarter had generalised OA, again associated with slightly (not significantly) increased hsCRP levels. Radiographic severity of OA

Table 1 Description of 770 consecutive patients with hip or knee joint replacement due to advanced OA

\begin{tabular}{|c|c|}
\hline Age (years), mean (SD) & $63(9)$ \\
\hline Body mass index $\left(\mathrm{kg} / \mathrm{m}^{2}\right)$, mean $(\mathrm{SD})^{*}$ & $28(4)$ \\
\hline Women, No (\%) & $481(62.5)$ \\
\hline \multicolumn{2}{|l|}{ Comorbidity, No (\%) } \\
\hline Hypertension† & $391(50.8)$ \\
\hline Coronary artery disease & $92(11.9)$ \\
\hline Congestive heart failure $\ddagger$ & $146(19.0)$ \\
\hline Impaired renal function§ & $117(15.2)$ \\
\hline Gout & $104(13.5)$ \\
\hline Diabetes** & $73(9.5)$ \\
\hline \multicolumn{2}{|l|}{ Drug use, No (\%) } \\
\hline NSAIDs & $345(44.8)$ \\
\hline Diuretics & $186(24.2)$ \\
\hline ACE inhibitors & $106(13.8)$ \\
\hline Lipid lowering agents & $35(4.5)$ \\
\hline Hormone replacement therapy†† & 59 (12.3) \\
\hline Heavy physical exertion (work or leisure), No (\%) & $210(27.3)$ \\
\hline \multicolumn{2}{|l|}{ Smoking } \\
\hline Never & $445(57.8)$ \\
\hline Former & $227(29.5)$ \\
\hline Current & $98(12.7)$ \\
\hline \multicolumn{2}{|l|}{ Alcohol consumption } \\
\hline None & $89(11.6)$ \\
\hline$<10 \mathrm{~g} /$ day & $413(53.8)$ \\
\hline$\geqslant=10 \mathrm{~g} /$ day & $266(34.6)$ \\
\hline \multicolumn{2}{|c|}{$\begin{array}{l}\text { *Weight divided by height squared; †systolic and/or diastolic blood } \\
\text { pressure } \geqslant 160 \text { or } \geqslant 95 \mathrm{~mm} \mathrm{Hg} \text {, respectively, and/or use of } \\
\text { antihypertensive drugs; } ¥ \text { medical history; sestimated (according to } \\
\text { Cockcroft and Gault formula }{ }^{18} \text { ) creatinine clearance below } 60 \mathrm{ml} / \mathrm{min} \\
(15 \text { th centile of overall distribution), information available for } 768 \\
\text { patients; } 9 \text { medical history of gout or use of uricosuric/uricostatic drugs } \\
\text { **history of diabetes or use of oral antidiabetics or insulin; †twomen } \\
\text { only. }\end{array}$} \\
\hline
\end{tabular}


Table 2 Mean serum hsCRP values in 770 consecutive patients with hip or knee joint replacement due to advanced $O A$ according to selected $O A$ characteristics

\begin{tabular}{|c|c|c|c|c|}
\hline Characteristics & No (\%) & $\begin{array}{l}\text { hsCRP (mg/l), } \\
\text { geometric mean }\end{array}$ & $\left(95 \% \mathrm{Cl}^{*}\right)$ & p Valuet \\
\hline Operated joint & & & & 0.7 \\
\hline Hip & 402 (52.2) & 2.5 & (2.3 to 2.8$)$ & \\
\hline Knee & $368(47.8)$ & 2.5 & $(2.2$ to 2.7$)$ & \\
\hline \multicolumn{5}{|l|}{ OA extent (radiographic) } \\
\hline Symmetry $\ddagger$ & & & & 0.3 \\
\hline Unilateral OA & $109(15.5)$ & 2.3 & (1.8 to 2.8$)$ & \\
\hline Bilateral OA & $593(84.5)$ & 2.5 & $(2.3$ to 2.7$)$ & \\
\hline Localisation§ & & & & 0.2 \\
\hline Localised OA & $449(73.0)$ & 2.3 & (2.1 to 2.5$)$ & \\
\hline Generalised OA & $166(27.0)$ & 2.6 & (2.2 to 3.0 ) & \\
\hline \multicolumn{5}{|l|}{ Radiographic severity of OA } \\
\hline Kellgren and Lawrence & & & & 0.9 \\
\hline Grade 3 & $271(36.6)$ & 2.5 & (2.2 to 2.8$)$ & \\
\hline Grade 4 & $470(63.4)$ & 2.5 & (2.3 to 2.8$)$ & \\
\hline \multicolumn{5}{|l|}{ OA severity (subjective) } \\
\hline Intensity of pain (mmVAS), median** & 73 & & & 0.009 \\
\hline$\leqslant 58$ & $154(20.3)$ & 2.0 & (1.7 to 2.3 ) & \\
\hline $59-\leqslant 69$ & $159(20.9)$ & 2.4 & $(2.0$ to 2.8$)$ & \\
\hline $70-\leqslant 78$ & 145 (19.1) & 2.5 & $(2.1$ to 3.0$)$ & \\
\hline $79-\leqslant 87$ & $155(20.4)$ & 2.7 & $(2.3$ to 3.2$)$ & \\
\hline$\geqslant 88$ & $147(19.3)$ & 3.1 & $(2.6$ to 3.6$)$ & \\
\hline Additional painful joint regions†† & & & & 0.02 \\
\hline None & $175(22.7)$ & 2.1 & $(1.8$ to 2.5$)$ & \\
\hline At least one & 595 (77.3) & 2.6 & $(2.4$ to 2.9$)$ & \\
\hline \multicolumn{3}{|c|}{ WOMAC $\neq \pm$ pain (0-20), median 12} & & 0.8 \\
\hline$\leqslant 9$ (least severe) & $147(23.7)$ & 2.2 & (1.9 to 2.7 ) & \\
\hline$>9-\leqslant 11$ & $131(21.2)$ & 2.5 & $(2.1$ to 3.0$)$ & \\
\hline$>11-\leqslant 14$ & $207(33.4)$ & 2.4 & $(2.1$ to 2.8$)$ & \\
\hline$>14$ (most severe) & $134(21.6)$ & 2.5 & $(2.1$ to 3.1$)$ & \\
\hline \multicolumn{3}{|l|}{ Walking } & & 0.3 \\
\hline None & $13(2.1)$ & 2.1 & (1.2 to 3.8$)$ & \\
\hline Mild & $63(10.1)$ & 2.1 & (1.6 to 2.7 ) & \\
\hline Moderate & 189 (30.3) & 2.2 & (1.9 to 2.6$)$ & \\
\hline Severe & 245 (39.3) & 2.8 & (2.5 to 3.2 ) & \\
\hline Extreme & 113 (18.1) & 2.2 & (1.7 to 2.7 ) & \\
\hline \multicolumn{3}{|l|}{ Stairs } & & 0.9 \\
\hline None & $6(1.0)$ & 5.1 & (1.8 to 15$)$ & \\
\hline Mild & $24(3.9)$ & 2.5 & (1.6 to 4.0 ) & \\
\hline Moderate & $133(21.3)$ & 2.4 & (2.0 to 2.9 ) & \\
\hline Severe & 299 (48.0) & 2.3 & (2.0 to 2.6 ) & \\
\hline Extreme & $161(25.8)$ & 2.7 & (2.3 to 3.1$)$ & \\
\hline \multicolumn{3}{|l|}{ Night } & & 0.9 \\
\hline None & 75 (12.1) & 2.3 & (1.8 to 2.9 ) & \\
\hline Mild & 139 (22.3) & 2.5 & $(2.1$ to 3.0$)$ & \\
\hline Moderate & $221(35.5)$ & 2.4 & (2.1 to 2.8 ) & \\
\hline Severe & $142(22.8)$ & 2.6 & (2.2 to 3.1$)$ & \\
\hline Extreme & 45 (7.2) & 2.1 & (1.5 to 2.8 ) & \\
\hline \multicolumn{3}{|l|}{ Sitting } & & 0.7 \\
\hline None & $73(11.8)$ & 2.4 & $(1.9$ to 3.0$)$ & \\
\hline Mild & $190(30.6)$ & 2.3 & (2.0 to 2.7 ) & \\
\hline Moderate & $237(38.2)$ & 2.5 & (2.2 to 2.8 ) & \\
\hline Severe & 107 (17.2) & 2.5 & (2.1 to 3.2$)$ & \\
\hline Extreme & $14(2.3)$ & 1.9 & $(1.1$ to 3.6$)$ & \\
\hline \multicolumn{3}{|l|}{ Standing } & & 0.6 \\
\hline None & $16(2.6)$ & 1.9 & (1.0 to 3.5$)$ & \\
\hline Mild & $48(7.7)$ & 2.2 & (1.7 to 2.9$)$ & \\
\hline Moderate & 202 (32.5) & 2.5 & (2.2 to 2.9$)$ & \\
\hline Severe & 249 (40.0) & 2.4 & (2.1 to 2.8 ) & \\
\hline Extreme & 107 (17.2) & 2.4 & $(2.0$ to 3.0$)$ & \\
\hline \multicolumn{5}{|c|}{ 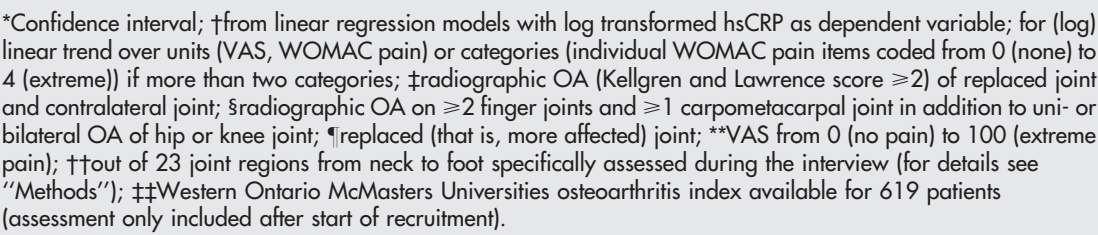 } \\
\hline
\end{tabular}

as assessed by the K\&L score was not associated with hsCRP levels in these patients with advanced OA.

The median severity of pain in the affected joint was 73 out of 100 on the VAS. A clear association between intensity of pain and hsCRP levels was seen with a monotonic increase in mean serum hsCRP with increasing pain severity. Patients reporting pain in a joint region in addition to the operated joint also had higher hsCRP levels. The median severity of pain during different tasks as assessed by the WOMAC was 12 out of 20. Neither pain, nor any of the five WOMAC pain items, nor any of the other dimensions of the WOMAC (data not presented) were associated with hsCRP levels.

Table 3 presents independent determinants of serum hsCRP levels, together with the mean percentage change in 
Table 3 Percentage change in mean hsCRP according to selected characteristics in 770 consecutive patients with hip or knee joint replacement due to advanced OA estimated from multivariable linear regression

\begin{tabular}{|c|c|c|}
\hline Characteristics & $\begin{array}{l}\text { Change in } \\
\text { mean } \\
\text { hsCRP (\%) }\end{array}$ & $(95 \% \mathrm{Cl})^{*}$ \\
\hline Age (10 year increase) & 9.3 & $(-0.4$ to 19.9$)$ \\
\hline Body mass index (5 unit increase) $\dagger$ & 22.3 & (12.1 to 33.4 ) \\
\hline Female sex & 25.9 & (3.7 to 52.8 ) \\
\hline \multicolumn{3}{|l|}{ Comorbidity } \\
\hline Hypertension $\ddagger$ & 3.7 & $(-12.7$ to 23.2$)$ \\
\hline Coronary artery disease & 14.0 & $(-9.8$ to 44.0$)$ \\
\hline Congestive heart failure§ & 2.9 & $(-16.1$ to 26.2$)$ \\
\hline Diabetes & 11.4 & $(-13.8$ to 44.0$)$ \\
\hline Use of diuretics & 34.0 & $(9.9$ to 63.3$)$ \\
\hline \multicolumn{3}{|l|}{ Smoking } \\
\hline Former & 35.8 & (13.6 to 62.5$)$ \\
\hline Current & 92.2 & (51.4 to 144 ) \\
\hline \multicolumn{3}{|l|}{ Alcohol consumption } \\
\hline None & 0.0 & Reference \\
\hline$<10 \mathrm{~g} /$ day & -2.8 & $(-23.3$ to 23.2$)$ \\
\hline$\geqslant 10 \mathrm{~g} /$ day & -5.5 & $(-28.4$ to 24.8$)$ \\
\hline $\begin{array}{l}\text { Intensity of pain ( } 10 \mathrm{mmVAS}{ }^{* *} \text { increase) } \\
\text { Intensity of pain (mmVAS }{ }^{* *} \text {, separate } \\
\text { model) }\end{array}$ & 5.7 & (1.1 to 10.4 ) \\
\hline$\leqslant 58$ & 0.0 & Reference \\
\hline $59-\leqslant 69$ & 13.7 & $(-9.0$ to 42.1$)$ \\
\hline $70-\leqslant 78$ & 17.0 & $(-6.8$ to 46.9$)$ \\
\hline $79-\leqslant 87$ & 20.0 & $(-4.5$ to 50.8$)$ \\
\hline$\geqslant 88$ & 35.5 & (7.4 to 70.8 ) \\
\hline Additional painful joint regions & 17.0 & $(-1.8$ to 39.5$)$ \\
\hline
\end{tabular}

${ }^{*} 95 \%$ Confidence interval for percentage change in geometric mean serum hsCRP level estimated from multivariable linear regression with log transformed hsCRP as dependent variable controlling (adjusting) for all variables presented in the table; †weight in $\mathrm{kg}$ divided by squared height in $\mathrm{m}$; ¥systolic and/or diastolic blood pressure $\geqslant 160$ or $\geqslant 95 \mathrm{mmHg}$, respectively, and/or use of antihypertensive drugs; §medical history - history of diabetes or use of oral antidiabetics or insulin; ${ }^{* *}$ VAS from 0 (no pain) to 100 (extreme pain).

serum hsCRP levels associated with the corresponding trait as estimated by multivariable linear regression. Only characteristics with a significant association with serum hsCRP in bivariate analyses were included in this multivariable model controlling for all variables presented in the table. Age $(9.3 \%$ higher mean hsCRP for every 10 year increase), body mass index $(22.3 \%$ higher mean for every five units increase), female sex (25.9\% higher mean), and current regular use of diuretics (34.0\% higher mean) were all independently associated with higher mean serum hsCRP levels. The most important independent predictor of serum hsCRP levels in patients with OA was smoking, especially current smoking, but former smokers also had significantly increased levels of serum hsCRP. Because a monotonic increase in serum hsCRP was observed with increasing intensity of pain (see table 2), the intensity of pain was included as a continuous variable. Every increase of $10 \mathrm{~mm}$ on the VAS was associated with a $5.7 \%$ increase in mean serum hsCRP (95\% CI 1.1 to 10.4 ). A separate analysis with intensity of pain categorised as quintiles again showed a monotonic increase in mean hsCRP values for increasing categories of pain. One or more painful joint region in addition to the region of the joint being replaced was associated with a $17.0 \%$ higher mean hsCRP (95\% CI -1.8 to 39.5$)$.

To further examine the association between pain, treatment of pain, and serum hsCRP values, we performed additional analyses stratifying the association between pain severity and hsCRP levels according to NSAID use. The patterns were essentially identical in patients without (adjusted elevation highest $v$ lowest quintile $=34 \%$, $\mathrm{p}=0.07$ ) and with current regular use of NSAIDs (adjusted elevation highest $v$ lowest quintile $=35 \%, \mathrm{p}=0.1$ ) .

\section{DISCUSSION}

Of all markers of severity and extent of OA assessed, intensity of pain was most strongly associated with low level rises in the mean serum hsCRP levels in this group of patients with advanced OA, whereas neither radiographic severity or extent, nor any dimension of the WOMAC were associated with serum hsCRP levels.

There is growing evidence that systemic markers of inflammation are associated with severity or clinical course of OA. Serum CRP, probably the most widely used clinical marker of systemic inflammation, has been shown to correlate well with CRP in synovial fluid in patients with OA or RA. ${ }^{19}$ Spector et al observed increased CRP values in women with radiographically defined knee OA in a population based, cross sectional study of 845 women in Chingford, as well as higher CRP values in women with radiographic OA progression during a four year follow up. ${ }^{4}$ The median hsCRP value found in our study $(2.5 \mathrm{mg} / \mathrm{l})$ is almost identical to the $2.4 \mathrm{mg} / \mathrm{l}$ observed by Spector et al.

Wolfe observed that disability (as assessed by the Health Assessment Questionnaire), number of tender joints, and pain were associated with higher mean CRP levels in 655 men and women with clinically defined OA of the hip or knee. $^{2}$ The result for pain is in agreement with the findings from our study. In contrast, we found no association between disability as assessed by the WOMAC nor radiographically defined generalised OA and mean hsCRP levels. Interestingly enough, the median CRP levels in the study by Wolfe were more than twice as high $(5.9 \mathrm{mg} / \mathrm{l})$ as in the study of Spector et al or in our study. This might be an indication that, despite the exclusion of patients with an erythrocyte sedimentation rate $>30 \mathrm{~mm} / \mathrm{lst} \mathrm{h}$, their clinically defined group of patients may still have included some patients with inflammation of unknown cause. Conrozier et $a l^{5}$ and Sharif $e t a l^{3}$ found that low level increases in CRP were associated with progression of hip OA and knee OA in small samples, respectively, but their results were either unadjusted ${ }^{5}$ or inconsistent. ${ }^{3}$

Although OA pain and radiographic findings correlate to some extent, many patients with advanced radiographic OA have no pain and a fair proportion of patients with pain show no radiographic signs of OA. ${ }^{20}$ Therefore, mechanical factors alone are insufficient to explain pain in OA. Because the sensation of pain in patients with OA is at least closely linked to, or may even be the result of, inflammatory processes, ${ }^{21}{ }^{22}$ the association between pain and hsCRP seems more plausible than an association between radiographic severity and hsCRP. Higher levels of both interleukin $1 \beta$ and tumour necrosis factor $\alpha$ have also been detected in sera from patients with other painful conditions, like cervicogenic headache. ${ }^{23}$ Tissue injury is known to result in the release of a variety of inflammatory mediators, including ions, bradykinin, histamine, 5-hydroxytryptamine, ATP, and nitric oxide. ${ }^{24}$ The activation of the arachidonic pathway may then lead to the production of prostanoids and leukotrienes, and recruited immune cells may release further mediators, including cytokines and growth factors. ${ }^{23}$

It is intriguing that we observed no association between any of the dimensions of the WOMAC and hsCRP levels, not even for the dimension of pain or any of the five pain items. In comparison with studies from Israel ${ }^{25}$ and America, ${ }^{26}$ which reported correlations between the WOMAC pain scale and pain assessed by a VAS of between 0.6 and 0.7 , the association was weaker in our study (0.4), but still well within the range (0.3-0.4) seen in the American study for all other correlations of pain measures used, including the WOMAC. It seems as if the individual integration of overall pain, like the one assessed by the VAS, might be a better marker of the underlying systemic process than the assessment of pain associated with different tasks like walking or 
climbing stairs. Furthermore, it has been reported that the WOMAC captures more than just knee or hip pain and is influenced by the presence of fatigue, depression, and low back pain. ${ }^{27}$ Because the WOMAC is sensitive to treatment of pain with analgesics or NSAIDs, ${ }^{28}$ it might be speculated that the treatment of pain does not influence the association between pain as assessed by the VAS and serum hsCRP levels. In our study we found no association between NSAID use and hsCRP, and the association between VAS and hsCRP was in fact independent of NSAID use in an additional multivariable analysis.

Our study did not include healthy controls. We were able, however, to compare the geometric mean serum hsCRP concentration in our patients with OA $(2.5 \mathrm{mg} / \mathrm{l})$ with that of 567 age and sex matched population controls $(1.7 \mathrm{mg} / \mathrm{l}$, adjusted difference $36 \%, \mathrm{p}<0.0001$ ) who were recruited for a national health and nutrition survey conducted among healthy people in the western part of Germany in 1987-88. ${ }^{7}$ Because some of the people in the national sample are likely to have had OA (no specific information or radiographs were available), this observed difference in mean hsCRP levels between patients with OA and population controls is more likely to be an underestimation than an overestimation of the true difference between patients with and without OA.

Despite the observation of diurnal variation of CRP in patients with $\mathrm{RA}^{, 29}$ high sensitivity CRP has been shown not to vary during the day in healthy people ${ }^{30}$ and to have a variability and classification accuracy similar to that of cholesterol screening. ${ }^{31}$ In combination with the use of a commercial kit calibrated with the WHO reference standard $85 / 506$, we therefore think that the hsCRP levels used in our study are a consistent measure of the underlying low grade systemic inflammatory process.

The limitations of our study need to be taken into account when interpreting our results. The cross sectional study design does not allow assessment of the prognostic value of hsCRP or the association between pain and hsCRP when using repeated measurements within a person. Although widely used to assess the intensity of pain in clinical and epidemiological settings, the measurement of pain using a VAS is influenced by a variety of factors associated with perception of pain. ${ }^{32}{ }^{33}$ Nevertheless, pain is always subjective and the observed associations provide evidence for this subjective phenomenon to be better associated with markers of low level systemic inflammation than any of the objective markers of OA assessed in our study. Because of our study design with inclusion restricted to patients with advanced OA, we could not assess the association between radiographic severity of OA and hsCRP levels. In our study group of patients with advanced OA, however, we observed no difference in mean hsCRP levels between patients with K\&L grades 3 and 4 . Finally, the pathology behind anamnestic pain in additional joint regions remains elusive.

We conclude that OA and the subjective severity of OA pain are associated with low level systemic inflammation as assessed by hsCRP in patients with advanced OA. Longitudinal studies with repeated assessments of hsCRP and pain within the course of OA from diagnosis to joint replacement are needed to assess the possible value of low level increases of hsCRP for monitoring or predicting the clinical course of OA and, finally, to evaluate its possible role in determining the best timing of joint replacement.

\section{ACKNOWLEDGEMENTS}

The study was supported by a research grant from the German Federal Ministry for Research and Technology (BMBF, 01 EF940/6).

\section{Authors' affiliations}

T Stürmer, H Brenner, Department of Epidemiology, German Centre for Research on Aging, Heidelberg, Germany

K-P Günther, Department of Orthopaedic Surgery (RKU), University of Ulm, Germany

W Koenig, Department of Internal Medicine II-Cardiology, University of Ulm, Germany

\section{REFERENCES}

1 Sun Y, Stürmer T, Günther KP, Brenner H. Inzidenz und Prävalenz der Coxund Gonarthrose in der Allgemeinbevölkerung [Incidence and prevalence of cox- and gonarthrosis in the general population]. Z Orthop Ihre Grenzgeb 1997; 135:184-92

2 Wolfe $\mathrm{F}$. The $\mathrm{C}$-reactive protein but not erythrocyte sedimentation rate is associated with clinical severity in patients with osteoarthritis of the knee or hip. J Rheumatol 1997;24:1486-8.

3 Sharif M, Elson CJ, Dieppe PA, Kirwan JR. Elevated serum C-reactive protein levels in osteoarthritis [letter]. Br J Rheumatol 1997;36:140-1.

4 Spector TD, Hart DJ, Nandra D, Doyle DV, Mackillop N, Gallimore JR, et al. Low-level increases in serum C-reactive protein are present in early osteoarthritis of the knee and predict progressive disease. Arthritis Rheum 1997;40:723-7.

5 Conrozier T, Chappuis-Cellier C, Richard M, Mathieu P, Richard S, Vignon E. Increased serum $C$-reactive protein levels by immunonephelometry in patients with rapidly destructive hip osteoarthritis. Rev Rheum Engl Ed 1998;65:759-65.

6 Frohlich $M$, Imhof A, Berg G, Hutchinson WL, Pepys MB, Boeing $H$, et al. Association between $\mathrm{C}$-reactive protein and features of the metabolic syndrome: a population-based study. Diabetes Care 2000;23:1835-9.

7 Imhof A, Froehlich M, Brenner H, Boeing H, Pepys MB, Koenig W. Effect of alcohol consumption on systemic markers of inflammation. Lancet 2001;357:763-7.

8 Arnett FC, Edworthy SM, Bloch DA, McShane DJ, Fries JF, Cooper NS, et al. The American Rheumatism Association 1987 revised criteria for the classification of rheumatoid arthritis. Arthritis Rheum 1988;31:315-24.

9 Günther KP, Stürmer T, Sauerland S, Zeissig I, Sun Y, Kessler S, et al. Prevalence of generalized osteoarthritis in patients with advanced hip and knee OA: the Ulm Osteoarthritis Study. Ann Rheum Dis 1998;57:717-23.

10 Günther KP, Scharf HP, Puhl W, Willauschus W, Sauerland S, Gluckert K, et al. Reproduzierbar keit der röntgenologischen Beurteilung von Coxarthrosen [Reproducibility in the roentgenological assessment of coxarthritis]. Z Orthop Ihre Grenzgeb 1997; 135:3-8.

11 Günther KP, Scharf HP, Puhl W, Willauschus W, Kalke Y, Gluckert K, et al. Reproduzierbar keit der radiologischen Diagnostik bei Gonarthrose [Reproducibility of radiologic diagnosis in gonarthrosis]. Z Orthop Ihre Grenzgeb 1997;135:197-202.

12 Kellgren JH, Lawrence JS. Radiological assessment of asteo-arthrosis. Ann Rheum Dis 1957; 16:494-502.

13 Empire Rheumatism Council. The epidemiology of chronic rheumatism. In: Atlas of standard radiographs of arthritis, Vol 2. Oxford: Blackwell Scientific Publications, 1963

14 Altman RD, Hochberg M, Murphy WA, Wolfe F, Lequesne M. Atlas of individual radiographic features in osteoarthritis. Osteoarthritis Cartilage 1995;3(suppl A):3-70.

15 Kessler S, Dieppe P, Fuchs J, Stürmer T, Günther KP. Assessing the prevalence of hand $\mathrm{OA}$ in epidemiological studies. The reliability of a new radiological hand scale. Ann Rheum Dis 2000;59:289-92.

16 Paul-Dauphin A, Guillemin F, Virion JM, Briancon S. Bias and precision in visual analogue scales: a randomized controlled trial. Am J Epidemiol 1999; 150:1117-27.

17 Bellamy N, Buchanan WW, Goldsmith CH, Campbell J, Stitt L. Validation study of WOMAC: a health status instrument for measuring clinicallyimportant patient-relevant outcomes following total hip or knee arthroplasty in osteoarthritis. J Orthop Rheumatol 1988;1:95-108.

18 Stürmer T, Erb A, Keller F, Günther KP, Brenner H. Nonsteroidal antiinflammatory drug use and renal function in patients with osteoarthritis. Am J Med 2001;111:521-7.

19 Kumon Y, Suehiro T, Nishiya K, Hashimoto K, Nakatani K, Sipe JD. Ferritin correlates with $C$-reactive protein and acute phase serum amyloid $A$ in synovial fluid, but not in serum. Int J Exp Clin Invest 1999;6:130-5.

20 Creamer $\mathbf{P}$, Hochberg MC. Why does osteoarthritis of the knee hurtsometimes? Br J Rheumatol 1997;36:726-8.

21 Merritt JL. Soft tissue mechanisms of pain in osteoarthritis. Semin Arthritis Rheum 1989;18(suppl 2):51-6.

22 Schumacher $\mathbf{R}$ Jr. The role of inflammation and crystals in the pain of osteoarthritis. Semin Arthritis Rheum 1989;18(suppl 2):81-5.

23 Martelletti P. Proinflammatory pathways in cervicogenic headache. Clin Exp Rheumatol 2000; 18(suppl 19):S33-8.

24 Kidd BL, Urban LA. Mechanisms of inflammatory pain. Br J Anaesth 2001:87:3-11.

25 Wigler I, Neumann L, Yaron M. Validation study of a Hebrew version of the WOMAC in patients with osteoarthritis of the knee. Clin Rheumatol 1999;18:402-5.

26 Creamer $\mathbf{P}$, Lethbridge-Cejku M, Hochberg M. Determinatns of pain severity in knee osteoarthritis: effect of demographic and psychosocial variables using 3 pain measures. J Rheumatol 1999;26:1785-92. 
27 Wolfe F. Determinants of WOMAC function, pain and stiffness scores: evidence for the role of low back pain, symptom counts, fatigue and depression in osteoarthritis, rheumatoid arthritis and fibromyalgia. Rheumatology (Oxford) 1999:38:355-61.

28 Bellamy N, Kean WF, Buchanan WW Gerecz-Simon E, Campbell J. Double blind randomized controlled trial of sodium meclofenamate (Meclomen) and diclofenac sodium (Voltaren): post validation reapplication of the WOMAC osteoarthritis index. J Rheumatol 1992;19:153-9.

29 Herold M, Gunther R. Circadian rhythm of C-reactive protein in patients with rheumatoid arthritis. Prog Clin Biol Res 1987;227B:271-9.
30 Meier-Ewert HK, Ridker PM, Rifai N, Price N, Dinges DF, Mullington JM Absence of diurnal variation of C-reactive protein concentrations in healthy human subjects. Clin Chem 2001;47:426-30.

31 Ridker PM. High sensitivity C-reactive protein: potential adjunct for global risk assessment in the primary prevention of cardiovascular disease. Circulation 2001;103:1813-18.

32 Woolf CJ, Decosterd I. Implications of recent advances in the understanding of pain pathophysiology for the assessment of pain in patients. Pain 1999;(supp 6): $5141-7$.

33 Katz J, Melzack R. Measurement of pain. Surg Clin North Am 1999;79:231-52.

\section{$\mathrm{ECHO}$}

\section{Knee symptoms common among men of working age}

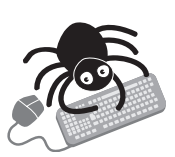

Please visit the Annals of the Rheumatic Diseases website [www. annrheumdis. com] for a link to the full text of this article. postal survey of working age men found that 54\% had ever had any knee symptoms, mostly pain and stiffness, and $14 \%$ had had to miss time from work because of it. Those whose jobs involved kneeling or squatting were more likely to have seen an orthopaedic surgeon. Meniscal injury was reported more often in those who played soccer and rugby and in those whose jobs involved kneeling, squatting, and frequent climbing of stairs.

The postal questionnaire was sent to a random sample of men aged 20-59. They were asked for their occupational and sporting history and history of knee symptoms lasting 24 hours or longer. The association of knee cartilage injury with sport and occupation was looked at by comparing all those who reported undergoing menisectomy with five randomly selected age-matched controls.

A total of 1404 men completed the survey (50\% response rate). Although $31 \%$ had seen a general practitioner about their knee symptoms, only 13\% had seen an orthopaedic surgeon. These men were more likely to be in jobs involving kneeling or squatting. Only $4.8 \%$ had undergone a menisectomy and a strong association was found with playing soccer and rugby and having a job involving kneeling, squatting and frequent climbing of stairs.

Findings from a community based survey such as this avoid the bias inherent in hospital studies. Although the response rate was low and the study subject to recall bias, it does show that hospital referral for knee symptoms is influenced by patients' occupational activities.

A Occupational and Environmental Medicine 2003;60:794-797. 